Editorial

\title{
Letter from the Editors: Special Issue on "Investigating Modern Slavery: How IB Scholarship Can Contribute”
}

\author{
Snejina Michailova, Guest Editor ${ }^{1}$, Christina Stringer, Guest Editor ${ }^{1}$, John Mezias, Editor ${ }^{2}$ \\ 1 The University of Auckland, New Zealand, 2 University of Miami, USA \\ Keywords: multinational corporations, international business scholarship, international business, modern slavery
}

\section{AIB Insights}

This Special Issue Commentary and Introduction briefly outlines how modern slavery is linked to international business via globally disaggregated production systems governed through ownership and contracts by MNCs. Numerous mechanisms and practices mask the presence of modern slavery across the globe. Uncovering modern slavery is a grand challenge that can and should be tackled by IB researchers and educators. Each of the Special Issue articles is devoted to different aspects of modern slavery and proposes how IB scholarship can address the phenomenon.

In 1981 the world celebrated abolishing slavery, with Mauritania being the last country to do so. However, modern slavery, an encompassing term for forced labor, human trafficking, and an array of other forms of labor exploitation, is alive and widespread. The full scale of modern slavery is unknown, but international organizations and foundations report tens of millions of people subject to forced labor conditions that generate billions of dollars in profits annually. These victims are treated as commodities; they are contractually, physically, and psychologically abused and exploited for economic gain.

Modern slavery is a global problem. It exists in developing and developed economies alike. It thrives in supply chains of commodity-based, labor-intensive industries like horticulture and construction, as well in high-tech sectors like electronics. It is embedded in a complex system that contributes to products we buy, consume and/or use every day. Modern slavery is inextricably linked to international business via globally disaggregated production systems governed through ownership and contracts by multinational corporations (MNCs). Numerous mechanisms and practices mask the presence of modern slavery. Uncovering this menace is a grand challenge that can and should be tackled by IB researchers and educators.

This issue's call for papers pointed out the paucity of IB research investigating modern slavery. We view this as an opportunity for authors. This call resonated with a number of scholars and we thank all those who submitted to this issue. While we could not publish all submissions, we are happy to feature four thought provoking articles in this Special Issue.

Our lead article, "Modern slavery responses need international business scholarship," authored by Alexander Trautrims, asks whether dealing with modern slavery is the responsibility of businesses or governments and outlines how these key actors can and should deal with the crime. He also argues that effective responses to modern slavery require changing business practices. It is illuminating, refreshing, and encouraging to hear from an outsider to the IB scholarly community why IB scholars are well positioned to research the phenomenon of modern slavery. He argues that the existence and persistence of modern slavery fundamentally questions key aspects of international business and highlights how injustice and human suffering benefit from greed and ignorance. Trautrims points out that IB scholars' expertise and knowledge of international organizations, their behaviors, logics, and decision-making processes offer unique opportunities to understand modern slavery in ways that are quite distinct from other disciplines. Researching modern slavery, according to Trautrims, must be problem-centric, practice-leading, and interdisciplinary. The latter feature requires a genuine openness to a variety of conceptual, theoretical, and methodological lenses, as well as teaching practices, and this includes leaving one's academic comfort zones and appreciating a diversity of approaches and perspectives.

Our second article focuses on how MNCs can avoid entanglement in modern slavery. Harry Van Buren III, Judith Schrempf-Sterling, and Michelle Westermann-Behaylo advise MNCs to clearly and continuously exercise ethical commitment. The authors highlight three types of responsibility-related reactions to enmeshment in modern slavery: implausible deniability, plausible deniability, and ethical commitment. Ethical commitment goes beyond satisfying technical standards and requirements by ensuring human rights violations are reduced and punished when these occur. In that sense, ethical commitment is an integrity-based approach, rather than one that merely satisfies and responds to formal rules and regulations. Just because MNCs operate in various contexts that often differ in regards to what is acceptable, appropriate, and ethical, it does not imply MNCs cannot ensure their practices and policies are designed so that the evil of modern slavery is not unknowingly part of their business. The authors highlight the need for future IB research to futher investigate how MNCs can avoid the entanglement of modern slavery.

Martijn Boersma and Justine Nolan's article provides insights into how blockchain technology can help uncover modern slavery in supply chains. While originally used to record cryptocurrency transactions, blockchain can record any transactions of value and is increasingly applied to prove the integrity of commodities and trace inputs' supply chain journey from the source to the end user. Such comprehensive tracking has great potential to identify supply chain actors that likely use slave labor. Touting blockchain as a way to identify modern slavery, Boersma and Nolan explore implications for companies engaged in multinational and transnational activities and in particular those companies extensively using sub-contracting networks. They outline five challenges - verification, inclusion, trust, privacy, and normativity - to using blockchain technology to ensure transparency in supply chains and ways companies can overcome these challenges. However, the authors acknowledge that blockchain by itself is not a silver bullet to erad- 
icate slavery. Indeed, they challenge those teaching IB to pose the question to their students as "digital natives" how blockchain can further unmask supply chain actors engaged in modern slavery.

The final article, by Swati Nagar and Fiona Hurd, addresses challenges faced by IB scholars interested in teaching the issue of modern slavery in the classroom. They highlight the paucity of articles in IB journals on modern slavery and related forms of exploitation. Nagar and Hurd provide insights into efforts to develop new teaching material and experiential strategies to study the issue of modern slavery and offer recommendations for teaching strategies, courses, and further lines of research to facilitate discussion of this important, but neglected topic. They propose that the IB scholarly community can and should develop a repository of teaching material, cases, media coverage, reports, etc. Developing a teaching repository and sharing best practices relate to using these materials, students will have the opportunity to gain a deeper understanding of modern slavery and other forms of exploitation that occur in MNCs' supply chains. Such a repository should also include materials on international human rights, fair work practices, and labor protection.

We hope you enjoy reading the Special Issue! We enjoyed putting it together for you. 